\title{
Effect of anemia and comorbidity on functional status and mortality in old age: results from the Leiden 85-plus Study
}

\author{
Wendy P.J. den Elzen MSc, Jorien M. Willems MD, Rudi G.J. Westendorp MD PhD, \\ Anton J.M. de Craen PhD, Willem J.J. Assendelft MD PhD, Jacobijn Gussekloo MD PhD
}

\section{ABSTRACT}

Background: There is limited insight into the attributable effect of anemia and comorbidity on functional status and mortality in old age.

Methods: The Leiden 85-plus Study is a population-based prospective follow-up study of 562 people aged 85 years. Anemia was defined according to World Health Organization criteria. We measured 3 parameters of functional status at baseline and annually thereafter for 5 years: disability in basic and instrumental activities of daily living, cognitive function and the presence of depressive symptoms. We obtained mortality data from the municipal registry.

Results: The prevalence of anemia at baseline was $26.7 \%$ (150/562). Participants who had anemia at baseline had more disability in activities of daily living, worse cognitive function and more depressive symptoms than participants without anemia at baseline $(p \leq 0.01)$. These differences disappeared after adjustment for comorbidity. After adjustment for comorbidity in the prospective analyses, anemia at baseline was associated with an additional increase in disability in instrumental activities of daily living during follow-up; incident anemia during follow-up $(n=99)$ was associated with an additional increase in disability in basic activities of daily living. Prevalent and incident anemia were both associated with an increased risk of death, even after we adjusted for sex, education level, income, residence in a long-term care facility, C-reactive protein level, creatinine clearance and the presence of disease (hazard ratio for prevalent anemia $1.41,95 \%$ confidence interval [CI] 1.13 to 1.76; hazard ratio for incident anemia 2.08, $95 \% \mathrm{Cl} 1.60$ to 2.70$)$.

Interpretation: Anemia in very elderly people appears to be associated with an increased risk of death, independent of comorbidity. However, the associated functional decline appears to be attributed mainly to comorbidity.

Une version française de ce résumé est disponible à l'adresse www.cmaj.ca/cgi/content/full/cmaj.090040/DC1

Cite as $C M A J$ 2009.DOI:10.1503/cmaj.090040
$\mathrm{I}$ $\mathrm{n}$ the past decade, anemia has been associated with a number of negative outcomes in elderly people. Not only is its presence a strong predictor of death, ${ }^{1-5}$ it has also been associated with various conditions such as decreased physical performance, disability in daily living, mobility disabilities, cognitive impairment, depression, falls and fractures, frailty, admission to hospital and diminished quality of life. ${ }^{6-8}$ Moreover, findings from studies involving patients with chronic heart failure have suggested that the development of incident or new-onset anemia has an even stronger effect on mortality than prevalent anemia. ${ }^{9-11}$ However, the attributable effect of incident anemia on mortality and functional status of elderly people in the general population has yet to be established.

Chronic conditions such as certain infections, inflammatory diseases, kidney disease and cancer are important causes of anemia via immune-driven processes. ${ }^{8,12-14}$ These chronic conditions are also associated with decreased functional status and mortality. However, it remains unclear whether anemia is an independent cause of functional decline and increased mortality, or whether the strong association between anemia and these 2 states can be explained by comorbidity. ${ }^{8,12-14}$ We conducted this study to examine the association between prevalent and incident anemia with functional status and mortality in a very elderly population. We also investigated the role of comorbidity in these associations. Data pertinent to our study were extracted from the wider Leiden 85-plus Study.

\section{Methods}

\section{Study population and procedures}

The present study was embedded in the Leiden 85-plus Study, a population-based prospective follow-up study of 85-yearold inhabitants of Leiden, the Netherlands. Leiden has a population of about 118000 inhabitants. In the Netherlands, all people living in the community are registered at a local gen-

From the Department of Public Health and Primary Care (den Elzen, Assendelft, Gussekloo) and the Department of Gerontology and Geriatrics (Willems, Westendorp, de Craen), Leiden University Medical Center, Leiden, the Netherlands 
eral practice and local pharmacy. Residents in nursing homes are cared for by a nursing home physician.

The study population has been described previously in more detail. ${ }^{15}$ In short, between September 1997 and September 1999, all inhabitants of Leiden of the 1912-1914 birth cohort were eligible for study participation. No one was excluded on the basis of health, cognitive functioning or living situation. Participants were visited annually (at age 85 through 90 years) at their place of residence to gather information in face-to-face interviews and to obtain venous blood samples. All participants gave their informed consent to take part in the study. For those who had severe cognitive impairment, informed consent was obtained from a proxy. The Medical Ethical Committee of the Leiden University Medical Center approved the study.

\section{Main study parameters}

\section{Anemia}

Blood samples were drawn before $11 \mathrm{am}$. Hemoglobin levels and mean corpuscular volume were determined on the day the sample was drawn with the use of an automated analysis system (Coulter Counter, Coulter Electronics, Hialeah, USA). Anemia was defined according to the criteria of the World Health Organization (hemoglobin level $<120 \mathrm{~g} / \mathrm{L}$ for women and $<130 \mathrm{~g} / \mathrm{L}$ for men). ${ }^{16}$ Prevalent anemia was defined as the presence of anemia at age 85 years (at baseline). Prevalent anemia was further divided into persistent anemia (the presence of anemia at age 85 and 86 years) and resolved anemia (anemia at age 85, no anemia at age 86 years). Incident anemia was defined as newly identified anemia after age 85 years in those without anemia at baseline.

\section{Functional status}

Disability in daily living was measured with the Groningen Activity Restriction Scale, which assesses an individual's competence in 18 activities of daily living. ${ }^{17}$ Questions are phrased: "Can you, fully independently, ...?" Answers range from "fully independently, without any difficulty" (1 point) to "not fully independently, only with someone's help" (4 points). Separate scores were calculated for 9 basic activities of daily living (total score 9-36) and 9 instrumental activities of daily living (total score 9-36). ${ }^{18}$ Basic activities of daily living included the following tasks: dressing oneself, washing hands and face, washing whole body, getting around the house, getting into and out of bed, standing up from a chair, going to the toilet, drinking and feeding oneself, and preparing breakfast. Instrumental activities included doing light housework, doing heavy household cleaning, washing and ironing clothes, making the bed, preparing a hot meal, going up and down stairs, getting around outdoors, doing the shopping, and attending to feet and toenails. ${ }^{18}$ For participants who had severe cognitive impairment, information was obtained from a proxy.

Cognitive function was measured with the Mini-Mental State Examination $;{ }^{19}$ scores range from 0 to 30, with lower scores indicating impaired cognitive functioning. Depressive symptoms were assessed with the 15-item Geriatric Depression Scale, a tool developed specifically to screen for depres- sive symptoms in elderly people ${ }^{20}$ scores range from 0 (optimal) to 15. The Geriatric Depression Scale was administered only to participants who had a Mini-Mental State Examination score greater than 18 points.

\section{Mortality}

We obtained mortality data from the municipal registry recorded between the start of the study and Feb. 1, 2008.

\section{Comorbidity}

We used 2 markers for comorbidity, a potential confounding variable in the relation between anemia, functional status and mortality. These markers were known (diagnosed) disease and unknown (undiagnosed) disease.

We obtained information on the presence of known disease at baseline from the participants' general practitioners, nursing home physicians, pharmacy records and laboratory findings. There was no measure of severity. Known diseases included stroke, myocardial infarction, severe cognitive impairment, diabetes mellitus, Parkinson disease, hip fracture, arthritis, obstructive lung disease and malignant disease. We considered severe cognitive impairment to be present on the basis of a diagnosis by the general practitioner or a MiniMental State Examination score of less than 19. We considered diabetes mellitus to be present if diagnosed by the primary care physician, if the nonfasting glucose level was greater than $11.0 \mathrm{mmol} / \mathrm{L}$, or if a participant was taking antidiabetic medication.

For unknown (undiagnosed) disease, we measured Creactive protein levels using a Hitachi 747 automated analyzer (Hitachi, Tokyo, Japan). We determined creatinine clearance using the Cockcroft-Gault equation. ${ }^{21}$

\section{Other parameters}

We obtained information on other possible confounding variables, including sex, level of education, income and residence in a long-term care facility. In addition, we interviewed participants about current and former smoking habits. We determined serum levels of vitamin $B_{12}$ and folate in one batch using the Dual Count Solid Phase No Boil Assay (Diagnostic Products Corporation, Los Angeles, USA). We determined ferritin levels using an immunologic assay (E170, Roche, Almere, the Netherlands).

\section{Statistical analysis}

\section{Cross-sectional analyses}

We compared differences between participants with and without anemia at baseline using the Mann-Whitney $U$ test (for continuous variables) or the $\chi^{2}$ test (for categorical variables).

We analyzed the relation between prevalent anemia and functional status at baseline and the possible confounding roles of socio-demographic characteristics and comorbidity using linear regression models. For each domain of functional status, we constructed 4 subsequent linear regression models, each model being an extension of the previous one. In the first model, we estimated crude differences in disability in basic activities of daily living, disability in instrumental activities of 
daily living, Mini-Mental State Examination scores and Geriatric Depression Scale scores between participants with and without anemia at baseline. The second model was an extension of the first whereby we adjusted for socio-demographic characteristics (sex, level of education, income and residence in long-term care facility). In the third model, we included additional adjustments for the presence of known disease. In the fourth model, we added adjustments for $\mathrm{C}$-reactive protein levels and creatinine clearance.

\section{Prospective analyses}

We used Cox proportional hazard models to investigate the association between prevalent anemia at baseline and mortality. To investigate the effect of prevalent anemia at baseline on changes in functional status during the follow-up period, we calculated individual annual changes in measures of functional status as the difference between the test score at baseline and the test score at the last available year of follow-up, divided by the length of follow-up for each participant (1-5 years). We investigated differences in annual changes between participants with and without anemia at baseline using linear regression analysis, with adjustment for possible confounding variables (sex, level of education, income, residence in long-term care facility, and the presence of known and unknown disease).

Among participants without anemia at baseline, we investigated the effect of incident anemia after the age of 85 years on mortality using time-dependent Cox proportional hazard models. To investigate the effect of incident anemia on functional decline during the follow-up period, we calculated the difference between the test scores at the point when anemia was first identified and the test scores at the last available year of follow-up, divided by the length of follow-up since the anemia was first identified (1-4 years). In this analysis, participants who did not have anemia during the follow-up period served as the reference group.

In addition, we used Cox models to compare the risk of death from age 86 onward between participants with persistent anemia and those whose anemia resolved.

\section{Results}

\section{Study population}

Between September 1997 and September 1999, 705 inhabitants of Leiden reached the age of 85 years and were eligible for participation in the study. Fourteen people died before enrolment in the study, and 92 refused to participate. Of those enrolled in the study, 7 died before blood samples could be collected, and 30 were unwilling to provide a blood sample. As a result, blood samples from 562 subjects were available for analysis at baseline ( $80 \%$ of those eligible). Figure 1 shows the number of participants at the outset of the study and annually over the 5-year follow-up period.

\section{Cross-sectional analyses}

The prevalence of anemia among the participants at age 85 years (i.e., at baseline) was $26.7 \%$ (150/562). Compared with the participants who did not have anemia $(n=412)$, those with anemia were more likely to be men, to be residing in a long-term care facility and to be former or current smokers (Table 1). In addition, participants with anemia presented with more known diseases, higher C-reactive protein levels and lower creatinine clearances than those without anemia.

Table 2 shows the cross-sectional differences in measures of functional status between participants with and without anemia. In the crude analyses (model 1), those with anemia had greater disability in basic and instrumental activities of daily living, lower Mini-Mental State Examination scores and higher Geriatric Depression Scale scores than their counterparts without anemia. Adjustments for socio-demographic characteristics

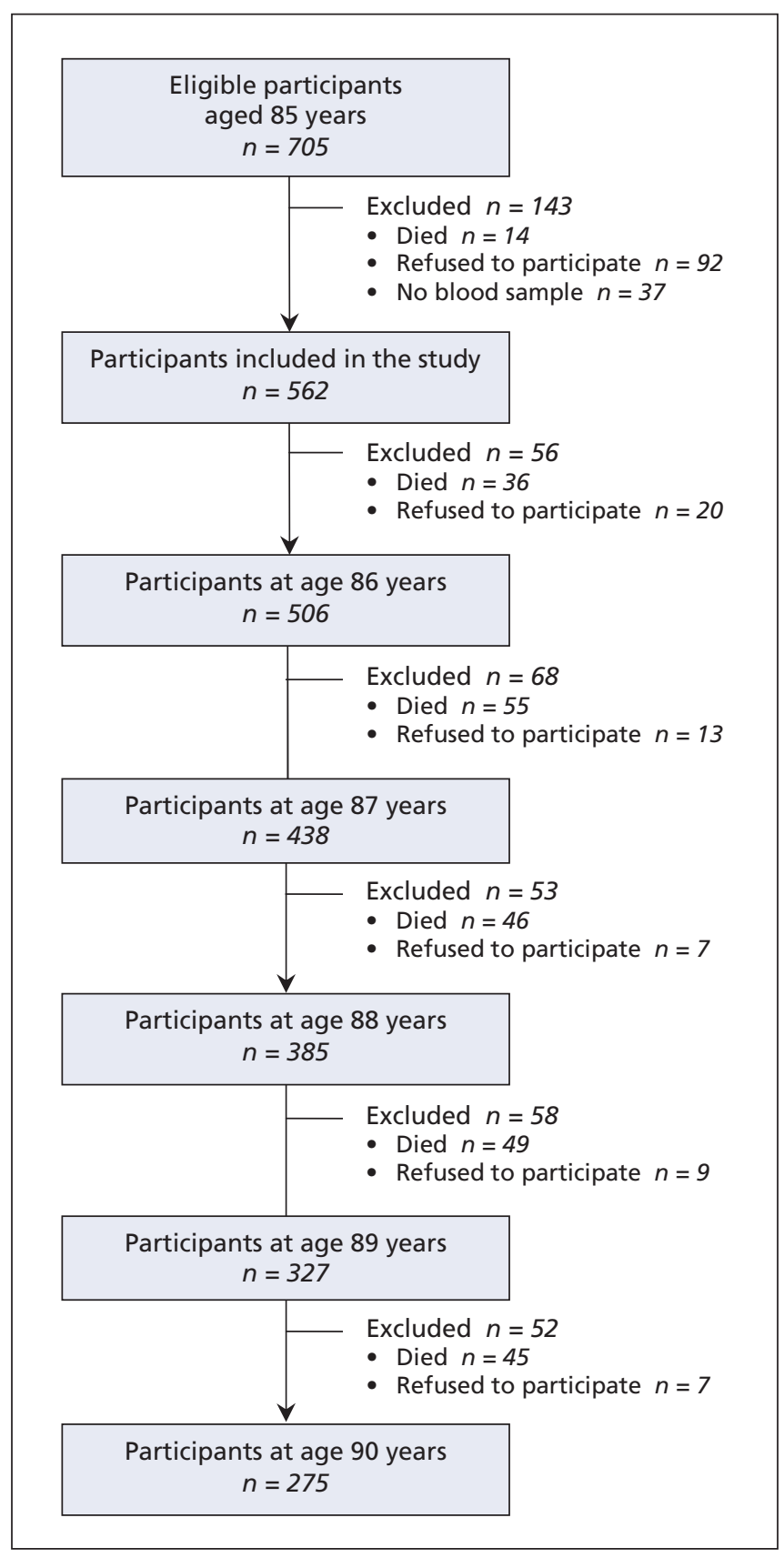

Figure 1: Number of participants at the outset of the study and annually thereafter for 5 years. 
Table 1: Baseline characteristics of the study population at age 85 years

\begin{tabular}{|c|c|c|c|c|}
\hline Characteristic & $\begin{array}{l}\text { Total population } \\
\qquad n=562\end{array}$ & $\begin{array}{l}\text { Anemia* at baseline } \\
\qquad n=150\end{array}$ & $\begin{array}{l}\text { No anemia at baseline } \\
\qquad n=412\end{array}$ & $p$ value \\
\hline \multicolumn{5}{|l|}{ Demographic characteristic } \\
\hline Sex, male, no. (\%) & $189(33.6)$ & $67(44.7)$ & $122(29.6)$ & $<0.01$ \\
\hline Low education level — primary school only, no. (\%) & $363(64.9)$ & $105(70.5)$ & $258(62.9)$ & 0.10 \\
\hline Low income level $-<€ 750$ per month, no. (\%) & $284(51.3)$ & $80(54.8)$ & $204(50.0)$ & 0.32 \\
\hline Residence in long-term care facility, no. (\%) & $102(18.1)$ & $39(26.0)$ & $63(15.3)$ & $<0.01$ \\
\hline Former or current smoker, no. (\%) & $272(49.2)$ & $87(59.2)$ & $185(45.6)$ & $<0.01$ \\
\hline \multicolumn{5}{|l|}{ Functional status } \\
\hline $\begin{array}{l}\text { Disability in basic activities of daily living, Groningen } \\
\text { Activity Restriction Scale score, median (IQR) }\end{array}$ & $10(9-15)$ & $10(9-17)$ & $10(9-13)$ & 0.01 \\
\hline $\begin{array}{l}\text { Disability in instrumental activities of daily living, } \\
\text { Groningen Activity Restriction Scale score, median (IQR) }\end{array}$ & $18(12-26)$ & $22(13-31)$ & $17(12-25)$ & $<0.01$ \\
\hline Mini-Mental State Examination score, median (IQR) & $26(22-28)$ & $25(20-28)$ & $26(23-28)$ & $<0.01$ \\
\hline Geriatric Depression Scale-15 score, median (IQR) & $2(1-3)$ & $2(1-4)$ & $1(0-3)$ & 0.01 \\
\hline \multicolumn{5}{|l|}{ Comorbidity } \\
\hline \multicolumn{5}{|l|}{ No. of known diseases, $†$ no. (\%) } \\
\hline 0 & $136(24.5)$ & $29(19.5)$ & $107(26.3)$ & \multirow{3}{*}{$<0.01$} \\
\hline 1 & $226(40.6)$ & $52(34.9)$ & $174(42.8)$ & \\
\hline$\geq 2$ & $194(34.9)$ & $68(45.6)$ & $126(31.0)$ & \\
\hline C-reactive protein level, mg/L, median (IQR) & $4(1-8)$ & $5(2-12)$ & $3(1-6)$ & $<0.01$ \\
\hline Creatinine clearance, $\mathrm{mL} / \mathrm{min}, \neq$ median (IQR) & $44.6(37.2-52.2)$ & $40.4(34.1-48.3)$ & $45.8(39.8-53.4)$ & $<0.01$ \\
\hline Vitamin $B_{12}$ level, pmol/L, median (IQR) & $274(188-379)$ & $269(171-397)$ & $274(192-378)$ & 0.96 \\
\hline Folate level, nmol/L, median (IQR) & $12.3(9.4-17.1)$ & $12.7 \quad(9.1-16.9)$ & $12.2(9.5-17.3)$ & 0.63 \\
\hline Ferritin level, $\mu \mathrm{g} / \mathrm{L}$, median (IQR) & $74(37-123)$ & $62(24-126)$ & $77(41-122)$ & 0.03 \\
\hline Mean corpuscular volume, fL, median (IQR) & $91(88-94)$ & 91 (88-94) & $92(88-95)$ & 0.05 \\
\hline
\end{tabular}

Note: IQR = interquartile range

*Anemia was defined according to the criteria of the World Health Organization: hemoglobin level $<120 \mathrm{~g} / \mathrm{L}$ for women and $<130 \mathrm{~g} / \mathrm{L}$ for men. ${ }^{16}$

tIncludes stroke, myocardial infarction, severe cognitive impairment, diabetes mellitus, Parkinson disease, hip fracture, arthritis, obstructive lung disease and malignant disease.

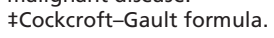

Table 2: Cross-sectional differences in measures of functional status between participants with and without anemia at baseline, before and after adjustment for possible confounders

\begin{tabular}{|c|c|c|c|c|c|c|c|c|}
\hline \multirow[b]{2}{*}{$\begin{array}{l}\text { Measure of } \\
\text { functional status }\end{array}$} & \multicolumn{2}{|c|}{$\begin{array}{c}\text { Model } 1 \\
\text { No adjustment* }\end{array}$} & \multicolumn{2}{|c|}{$\begin{array}{c}\text { Model } 2 \\
\text { Adjustment for } \\
\text { socio-demographic } \\
\text { characteristicst }\end{array}$} & \multicolumn{2}{|c|}{$\begin{array}{c}\text { Model } 3 \\
\text { Adjustment in model } 2 \\
\text { plus presence of known } \\
\text { disease } \neq\end{array}$} & \multicolumn{2}{|c|}{$\begin{array}{c}\text { Model } 4 \\
\text { Adjustment in model } 3 \\
\text { plus other parameters of } \\
\text { unknown disease§ }\end{array}$} \\
\hline & $\begin{array}{l}\text { Difference } \\
(95 \% \mathrm{Cl})\end{array}$ & $p$ value & $\begin{array}{l}\text { Difference } \\
(95 \% \mathrm{Cl})\end{array}$ & $p$ value & $\begin{array}{l}\text { Difference } \\
(95 \% \mathrm{Cl})\end{array}$ & $p$ value & $\begin{array}{l}\text { Difference } \\
(95 \% \mathrm{Cl})\end{array}$ & $p$ value \\
\hline $\begin{array}{l}\text { Disability in basic } \\
\text { activities of daily living }\end{array}$ & $2.0(0.9$ to 3.2$)$ & $<0.01$ & 1.3 (0.3 to 2.3 ) & 0.01 & 1.1 (0.1 to 2.1$)$ & 0.04 & 0.5 (-0.5 to 1.4$)$ & 0.32 \\
\hline $\begin{array}{l}\text { Disability in instrumental } \\
\text { activities of daily living }\end{array}$ & 2.9 (1.3 to 4.5$)$ & $<0.01$ & 1.7 (0.3 to 3.2 ) & 0.02 & $1.2(-0.1$ to 2.6$)$ & 0.08 & 0.8 (-0.7 to 2.2 ) & 0.30 \\
\hline $\begin{array}{l}\text { Mini-Mental State } \\
\text { Examination }\end{array}$ & $-1.8(-3.0$ to -0.7$)$ & $<0.01$ & $-1.1(-2.1$ to -0.1$)$ & 0.03 & $-0.9(-1.9$ to 0.1$)$ & 0.08 & $-0.4(-1.4$ to 0.6$)$ & 0.43 \\
\hline $\begin{array}{l}\text { Geriatric Depression } \\
\text { Scale-15 }\end{array}$ & 0.5 (0.0 to 1.0$)$ & 0.06 & 0.3 (-0.2 to 0.9$)$ & 0.19 & $0.3(-0.2$ to 0.9$)$ & 0.21 & 0.3 (-0.2 to 0.9 ) & 0.20 \\
\hline
\end{tabular}

*Crude analysis.

tAdjusted for socio-demographic characteristics (sex, level of education, income and residence in long-term care facility) at baseline.

¥Additional adjustments for the presence of known disease (including stroke, myocardial infarction, severe cognitive impairment, diabetes mellitus, Parkinson disease, hip fracture, arthritis, obstructive lung disease and malignant disease) at baseline.

$\S$ Additional adjustments for other parameters of unknown disease (C-reactive protein level and creatinine clearance) at baseline. 
(model 2) reduced the differences between the 2 groups; however, the differences in disability in basic and instrumental activities of daily living and in Mini-Mental State Examination scores remained statistically significant. Additional adjustment for known disease (model 3) further reduced the differences between the 2 groups. After including C-reactive protein levels and creatinine clearance (model 4), no differences between participants with and without anemia remained.

\section{Prospective analyses}

The participants who had anemia at baseline were at greater risk of death than those without anemia at baseline (hazard ratio $[\mathrm{HR}] 1.71,95 \%$ confidence interval $[\mathrm{CI}] 1.40$ to 2.10 ). This difference remained after adjustment for various confounding factors, including comorbidity (HR 1.41, 95\% CI 1.13 to 1.76 ) (Table 3). Exclusion of 96 participants who were using vitamin $\mathrm{B}_{12}$, folic acid, iron or erythropoietin supplements at baseline or during follow-up did not change the results (data not shown). We found that the risk of death associated with prevalent anemia was similar among men and women, and among participants in long-term care facilities and those living independently in the community. A doseresponse relation between severity of anemia and mortality was observed when participants with prevalent anemia were divided into groups with mild $(n=98)$, moderate $(n=30)$ and severe anemia $(n=22)$ (Table $4, p$ for trend $<0.01)$.

Participants with and without anemia at baseline did not show differences in functional decline during follow-up in the crude analyses (difference in annual change: Groningen Activity Restriction Scale score for disability in basic activities of daily living $0.5,95 \% \mathrm{CI}-0.1$ to $1.0, p=0.08$; Groningen Activity Restriction Scale score for disability in instrumental activities of daily living $0.5,95 \% \mathrm{CI}-0.1$ to $1.1, p=0.10$; Mini-Mental State Examination score -0.3 , 95\% CI -0.7 to $0.1, p=0.13$; and Geriatric Depression Scale score 0, 95\% CI -0.3 to $0.3, p=0.84$ ). In the adjusted analyses, anemia was associated with a significant additional increase in disability in instrumental activities of daily living (adjusted difference in annual change: Groningen Activity Restriction Scale score for disability in basic activities of daily living $0.5,95 \% \mathrm{CI}-0.1$ to 1.1, $p=0.09$; Groningen Activity Restriction Scale score for disability in instrumental activities of daily living $0.7,95 \% \mathrm{CI}$ 0.1 to $1.4, p=0.03$; Mini-Mental State Examination score

Table 3: Effect of anemia on mortality

\begin{tabular}{lcc}
\hline & \multicolumn{2}{c}{ Hazard ratio $(95 \% \mathrm{Cl})$} \\
\cline { 2 - 3 } Anemia & Crude & Adjusted* \\
\hline $\begin{array}{l}\text { Prevalent anemia } \\
(n=150 / 562)\end{array}$ & $1.71(1.40$ to 2.10$)$ & $1.41(1.13$ to 1.76$)$ \\
$\begin{array}{l}\text { Incident anemia } \\
(n=99 / 412)\end{array}$ & $2.16(1.68$ to 2.77$)$ & $2.08(1.60$ to 2.70$)$ \\
\hline
\end{tabular}

Note: $\mathrm{Cl}=$ confidence interval.

*Adjusted for sex, level of education, income, residence in long-term care facility, presence of 1 or more known diseases (including stroke, myocardial infarction, severe cognitive impairment, diabetes mellitus, Parkinson disease, hip fracture, arthritis, obstructive lung disease and malignant disease),

C-reactive protein level and creatinine clearance at baseline.
$-0.3,95 \%$ CI -0.7 to $0.2, p=0.24$; and Geriatric Depression Scale score $-0.1,95 \% \mathrm{CI}-0.4$ to $0.2, p=0.59$ ).

Incident anemia developed during the follow-up period in $99(24.0 \%)$ of the 412 participants without anemia at baseline (1329 person-years at risk, incidence $7.4 \%$ per year). These 99 participants had a 2 -fold increased risk of death compared with participants in whom anemia did not develop during follow-up (crude HR 2.16, 95\% CI 1.68 to 2.77; adjusted HR $2.08,95 \%$ CI 1.60 to 2.70 ) (Table 3 ).

Participants with incident anemia had a greater increase in disability in basic activities in daily living compared with participants who did not have anemia during follow-up (difference in annual change in Groningen Activity Restriction Scale score $1.7,95 \%$ CI 0.8 to $2.7, p<0.01$ ). Incident anemia was not associated with changes in the other parameters of functional status (difference in annual change in Groningen Activity Restriction Scale score for instrumental activities of daily living $-0.4,95 \% \mathrm{CI}-1.2$ to $0.3, p=0.28$; Mini-Mental State Examination score $-0.5,95 \%$ CI -1.1 to $0.1, p=0.10$; and Geriatric Depression Scale score $0.1,95 \%$ CI -0.4 to 0.6 , $p=0.60)$. When we adjusted for sex, level of education, income, residence in a long-term care facility, the presence of known disease, C-reactive protein levels, and creatinine clearance, we found that incident anemia was still associated with an additional increase in disability in basic activities of daily living (adjusted difference in annual change in Groningen Activity Restriction Scale score for basic activities of daily living $1.4,95 \%$ CI 0.4 to $2.5 ; p<0.01$ ).

The risk of death did not differ significantly between the 43 participants with anemia at baseline that resolved during follow-up and the 78 participants whose anemia persisted (crude HR 1.06, 95\% CI 0.71 to 1.59 ; adjusted HR $1.27,95 \%$ CI 0.82 to 1.98 ).

\section{Interpretation}

In our population-based study of very elderly people, we found that both prevalent anemia in individuals at the age of 85 years

Table 4: Effect of anemia at baseline on mortality, by severity of anemia

\begin{tabular}{|c|c|c|}
\hline \multirow[b]{2}{*}{ Severity of anemia* } & \multicolumn{2}{|c|}{ Hazard ratio $(95 \% \mathrm{Cl})$} \\
\hline & Crude & Adjusted $†$ \\
\hline No anemia $(n=412)$ & 1.00 (ref) & 1.00 (ref) \\
\hline Mild $(n=98)$ & $1.37(1.08-1.75)$ & $1.27(0.99-1.64)$ \\
\hline Moderate $(n=30)$ & $2.46(1.68-3.60)$ & $1.50 \quad(0.98-2.29)$ \\
\hline Severe $(n=22)$ & $4.13(2.64-6.45)$ & $2.93(1.72-4.98)$ \\
\hline$p$ value for trend & $<0.01$ & $<0.01$ \\
\hline
\end{tabular}

Note: $\mathrm{Cl}=$ confidence interval.

*Mild anemia: hemoglobin 110-119 g/L for women and 120-129 g/L for men; moderate anemia: hemoglobin 100-109 g/L for women and 110-119 g/L for men; severe anemia: hemoglobin $<100 \mathrm{~g} / \mathrm{L}$ for women and $<110 \mathrm{~g} / \mathrm{L}$ for men. †Adjusted for sex, level of education, income, residence in a long-term care facility, presence of $\geq 1$ known diseases (including stroke, myocardial infarction, severe cognitive impairment, diabetes, Parkinson disease, hip fracture, arthritis, obstructive lung disease and malignant disease), C-reactive protein levels and creatinine clearance at baseline. 
and incident anemia in the years thereafter was associated with an increased risk of death, independent of the presence of comorbid disease. We found associations between anemia and functional status, most of which disappeared after adjustments for comorbid conditions, including unknown disease.

Because chronic disease is often accompanied by anemia, it is a classic confounder in analyses of the association between anemia, functional decline and mortality. ${ }^{22}$ Therefore, we chose rigorous statistical methods to adjust for the presence of disease, both known and yet unknown to the general practitioner. The strong link between anemia and functional status disappeared after we adjusted for the presence of disease.

These results do not necessarily imply that anemia has no independent effect on functional decline. In our study, chronic disease can be regarded as either a confounder or as an important first step in the causal pathway from chronic disease to functional decline, with anemia as an intermediate step..$^{22}$ In the latter case, we adjusted for a factor in the causal pathway that may have led to an underestimation of the true association between anemia and functional status. As a result, as in other observational studies, we do not know which model — the crude model or the fully adjusted model — was the best reflection of the true effect of anemia on functional decline. This may well explain the inconsistent results in other population-based studies of anemia and disability, ${ }^{23-27}$ anemia and cognitive impairment or dementia, , $, 23,28,29^{2}$ and anemia and depression ${ }^{23,24,30}$ in elderly individuals. These studies all used different levels of control for the confounding effects of comorbidity. Only a randomized controlled trial, in which the role of chronic disease can be eliminated, would show whether correction of hemoglobin levels (e.g., with blood transfusions or erythropoietin) in older people in the general population improves functional status and increases the length and quality of life.

We found a strong, independent association between prevalent anemia in participants at age 85 years and risk of death. This finding confirms the results of previous studies involving elderly people living in the community in the Netherlands, ${ }^{1}$ the United States ${ }^{2-4}$ and Canada. ${ }^{5}$ We found that incident anemia in participants beyond the age of 85 years had an even stronger impact on mortality than prevalent anemia at age 85 . This finding concurs with results from studies involving patients with chronic heart failure. ${ }^{9-11}$

Our study has several strengths. Its prospective design allowed us to look into the effect of incident anemia. In addition, the population-based setting and almost complete followup of our participants permitted us to generalize our conclusions to very elderly people in the general population at large.

Our study considered people aged 85 years. It is important to study the impact of anemia in old age specifically, because the very elderly are the fastest growing segment of the general population and the prevalence of anemia increases with age. ${ }^{31}$ Therefore, anemia in old age can have a significant effect on health care needs and costs in our aging society. ${ }^{32}$ However, our results should not be extrapolated to younger populations, because the risk of common determinants of disease and mortality vary largely in different age groups. Negative effects of hypothyroidism, hypertension and hypercholes- terolemia have already been shown to reverse or disappear in the oldest old. ${ }^{33-35}$ Nevertheless, because anemia was associated with an increased risk of death in our study population of 85 -year-old people, older ( $\geq 85$ years) and younger populations may not differ substantially with respect to the impact of anemia on mortality.

\section{Conclusion}

Although future randomized controlled trials are needed to look into the true and independent effect of the treatment of anemia on mortality and functional decline in the elderly population, the results of our study suggest that anemia in very elderly people is associated with an increased risk of death, independent of comorbidity. The associated functional decline appears to be mainly attributed to comorbid illnesses.

This article has been peer reviewed.

Competing interests: None declared.

Contributors: Rudi Westendorp and Jacobijn Gussekloo were responsible for the study concept and design; Rudi Westendorp, Anton de Craen and Jacobijn Gussekloo acquired the data; Wendy den Elzen and Jacobijn Gussekloo drafted the manuscript; Wendy den Elzen, Rudi Westendorp, Anton de Craen and Jacobijn Gussekloo performed the statistical analysis; Rudi Westendorp, Anton de Craen, Willem Assendelft and Jacobijn Gussekloo supervised the study; Wendy den Elzen, Anton de Craen and Jacobijn Gussekloo provided administrative, technical and material support; Rudi Westendorp and Jacobijn Gussekloo obtained funding. All of the authors analyzed and interpreted the data, critically revised the manuscript for important intellectual content and approved the final version submitted for publication.

Acknowledgements: The Leiden 85-plus Study is a collaborative project of the Department of Gerontology and Geriatrics (Rudi Westendorp, principal investigator) and the Department of Public Health and Primary Care (Jacobijn Gussekloo, principal investigator) of the Leiden University Medical Center, Leiden, the Netherlands.

Funding: The Leiden 85-plus Study was funded in part by the Dutch Ministry of Health, Welfare and Sports.

\section{REFERENCES}

1. Izaks GJ, Westendorp RG, Knook DL. The definition of anemia in older persons. JAMA 1999;281:1714-7.

2. Chaves PH, Xue QL, Guralnik JM, et al. What constitutes normal hemoglobin concentration in community-dwelling disabled older women? J Am Geriatr Soc 2004; 52:1811-6.

3. Denny SD, Kuchibhatla MN, Cohen HJ. Impact of anemia on mortality, cognition, and function in community-dwelling elderly. Am J Med 2006;119:327-34.

4. Zakai NA, Katz R, Hirsch C, et al. A prospective study of anemia status, hemoglobin concentration, and mortality in an elderly cohort: the Cardiovascular Health Study. Arch Intern Med 2005;165:2214-20.

5. Culleton BF, Manns BJ, Zhang J, et al. Impact of anemia on hospitalization and mortality in older adults. Blood 2006;107:3841-6.

6. Beghé C, Wilson A, Ershler WB. Prevalence and outcomes of anemia in geriatrics: a systematic review of the literature. Am J Med 2004;116 (Suppl 7A):3S-10S.

7. Eisenstaedt R, Penninx BW, Woodman RC. Anemia in the elderly: current understanding and emerging concepts. Blood Rev 2006;20:213-26.

8. Lipschitz D. Medical and functional consequences of anemia in the elderly. $J \mathrm{Am}$ Geriatr Soc 2003;51(Suppl 3):S10-3.

9. Ishani A, Weinhandl E, Zhao Z, et al. Angiotensin-converting enzyme inhibitor as a risk factor for the development of anemia, and the impact of incident anemia on mortality in patients with left ventricular dysfunction. J Am Coll Cardiol 2005;45: 391-9.

10. Komajda M, Anker SD, Charlesworth A, et al. The impact of new onset anaemia on morbidity and mortality in chronic heart failure: results from COMET. Eur Heart J 2006;27:1440-6.

11. Tang WH, Tong W, Jain A, et al. Evaluation and long-term prognosis of newonset, transient, and persistent anemia in ambulatory patients with chronic heart failure. J Am Coll Cardiol 2008;51:569-76.

12. Maraldi C, Ble A, Zuliani G, et al. Association between anemia and physical disability in older patients: role of comorbidity. Aging Clin Exp Res 2006;18:485-92. 
13. Zarychanski R, Houston DS. Anemia of chronic disease: A harmful disorder or an adaptive, beneficial response? CMAJ 2008;179:333-7.

14. Weiss G, Goodnough LT. Anemia of chronic disease. N Engl J Med 2005;352: 1011-23.

15. der Wiel AB, van Exel E, de Craen AJ, et al. A high response is not essential to prevent selection bias: results from the Leiden 85-plus study. J Clin Epidemiol 2002;55:1119-25.

16. Nutritional anaemias. Report of a WHO scientific group. World Health Organ Tech Rep Ser 1968;405:5-37.

17. Kempen GI, Miedema I, Ormel J, et al. The assessment of disability with the Groningen Activity Restriction Scale. Conceptual framework and psychometric properties. Soc Sci Med 1996;43:1601-10.

18. Bootsma-van der Wiel A, Gussekloo J, de Craen AJ, et al. Disability in the oldest old: "Can do" or "do do"? J Am Geriatr Soc 2001;49:909-14.

19. Heeren TJ, Lagaay AM, von Beek WC, et al. Reference values for the MiniMental State Examination (MMSE) in octo- and nonagenarians. J Am Geriatr Soc 1990;38:1093-6.

20. Yesavage JA, Brink TL, Rose TL, et al. Development and validation of a geriatric depression screening scale: a preliminary report. J Psychiatr Res 1982;17:37-49.

21. Cockcroft DW, Gault MH. Prediction of creatinine clearance from serum creatinine. Nephron 1976;16:31-41.

22. Rothman KJ. Biases in study design. In: Epidemiology: an introduction. New York (NY): Oxford University Press; 2002. p. 94-112.

23. Lucca U, Tettamanti M, Mosconi P, et al. Association of mild anemia with cognitive, functional, mood and quality of life outcomes in the elderly: the "Health and Anemia" study. PLoS ONE 2008;3(4):e1920.

24. Ishine M, Wada T, Akamatsu K, et al. No positive correlation between anemia an disability in older people in Japan. J Am Geriatr Soc 2005;53:733-4.

25. Chaves PH, Ashar B, Guralnik JM, et al. Looking at the relationship between hemoglobin concentration and prevalent mobility difficulty in older women Should the criteria currently used to define anemia in older people be reevaluated? J Am Geriatr Soc 2002;50:1257-64.

26. Penninx BW, Pahor M, Cesari M, et al. Anemia is associated with disability and decreased physical performance and muscle strength in the elderly. $J$ Am Geriat Soc 2004;52:719-24.

27. Penninx BW, Guralnik JM, Onder G, et al. Anemia and decline in physical performance among older persons. Am J Med 2003;115:104-10.

28. Atti AR, Palmer K, Volpato S, et al. Anaemia increases the risk of dementia in cognitively intact elderly. Neurobiol Aging 2006;27:278-84.

29. Chaves PH, Carlson MC, Ferrucci L, et al. Association between mild anemia and executive function impairment in community-dwelling older women: The Women's Health and Aging Study II. J Am Geriatr Soc 2006;54:1429-35.

30. Onder G, Penninx BW, Cesari M, et al. Anemia is associated with depression in older adults: results from the InCHIANTI study. J Gerontol A Biol Sci Med Sci 2005;60:1168-72.

31. Guralnik JM, Eisenstaedt RS, Ferrucci L, et al. Prevalence of anemia in persons 65 years and older in the United States: evidence for a high rate of unexplained anemia. Blood 2004; 104:2263-8.

32. Robinson B. Cost of anemia in the elderly. J Am Geriatr Soc 2003;51(Suppl 3): S14-7.

33. Gussekloo J, van Exel E, de Craen AJ, et al. Thyroid status, disability and cognitive function, and survival in old age. JAMA 2004;292:2591-9.

34. van Bemmel T, Gussekloo J, Westendorp RG, et al. In a population-based prospective study, no association between high blood pressure and mortality after age 85 years. J Hypertens 2006;24:287-92.

35. Weverling-Rijnsburger AW, Blauw GJ, et al. Total cholesterol and risk of mortality in the oldest old. Lancet 1997;350:1119-23.

Correspondence to: Wendy P.J. den Elzen, Department of Public Health and Primary Care, Leiden University Medical Center, Post zone V-0-P, PO Box 9600, 2300 RC Leiden, the Netherlands; fax0031-71-526-8259; w.p.j.den_elzen@lumc.nl

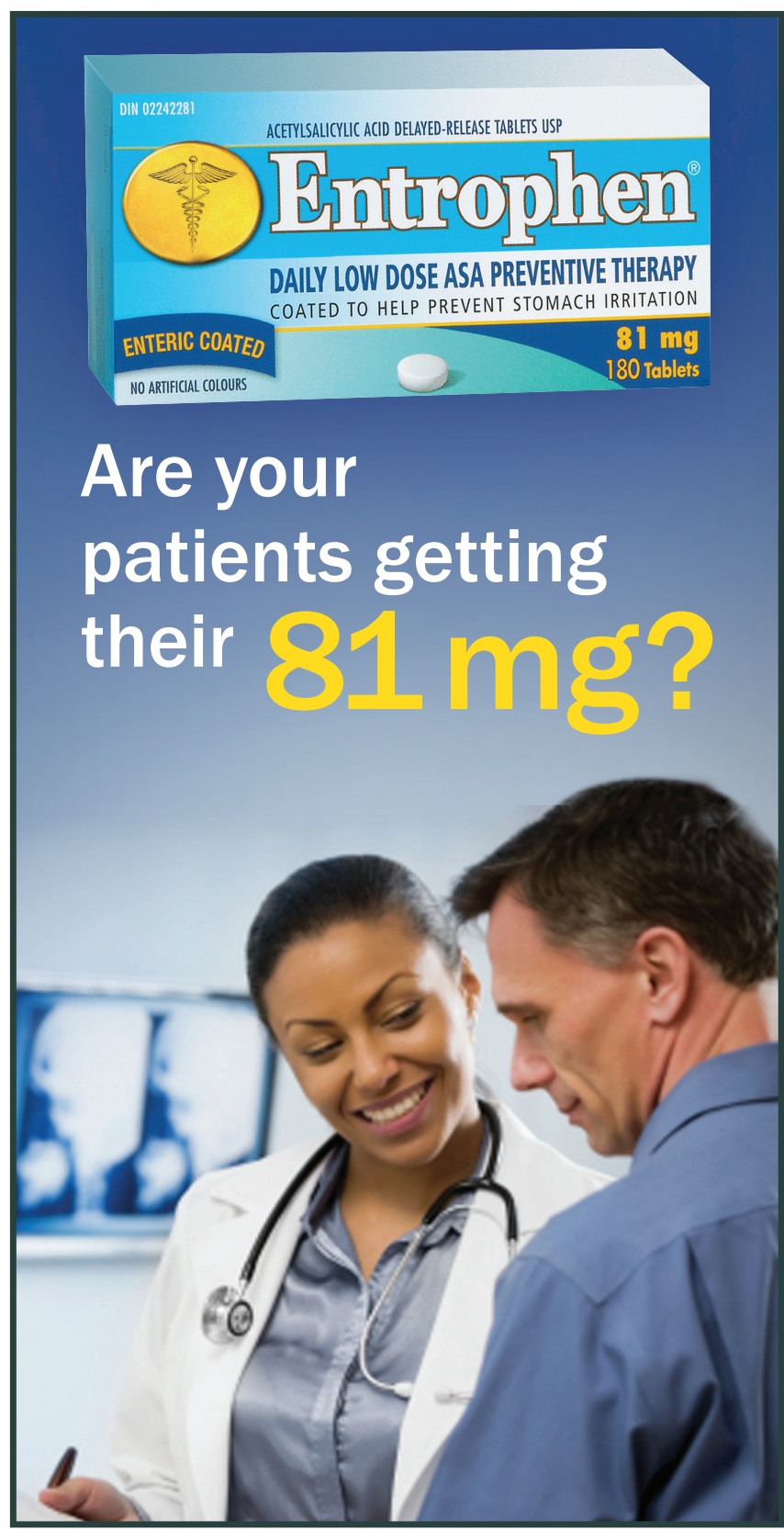

Entrophen $81 \mathrm{mg}$ is indicated for reducing the risk of a first non-fatal myocardial infarction in individuals deemed to be at sufficient risk of such an event by their physician. There is no evidence for a reduction in the risk of first fatal myocardial infarction. ASA does not reduce the risk of either cardiovascular mortality or first strokes, fatal or nonfatal. The decrease in the risk of first non-fatal myocardial infarction must be assessed against a much smaller but significant increase in the risk of haemorrhagic stroke as well as gastrointestinal bleeding.

Please refer to the product monograph for full indications, contraindications, warnings, adverse events, and patient selection criteria.

${ }^{\circledR}$ Registered Trademark of PendoPharm,

Division of Pharmascience Inc. Montréal, CANADA H4P 2T4

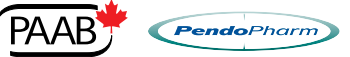

See prescribing summary on page $x x x$ 